\title{
Overweight and Underweight Prevalence Trends in Children from Romania - Pooled Analysis of Cross-Sectional Studies between 2006 and 2015
}

\author{
Adela Chirita-Emandi ${ }^{a}$ Carmen Gabriela Barbu ${ }^{b, c}$ Elena Eliza Cinteza ${ }^{d, e}$ \\ Bianca Ioana Chesaru $^{f}$ Mihai Gafencug Veronica Mocanu ${ }^{h}$ Ionela M. Pascanu ${ }^{i}$ \\ Simona Alexandra Tatarj Mihaela Balgradean ${ }^{d, k}$ Michaela Dobre ${ }^{f}$ \\ Simona Vasilica Fica ${ }^{b, c}$ Gabriela Edita Ichim ${ }^{j}$ Raluca Popl Maria Puiu ${ }^{a}$ m \\ ${ }^{a}$ Genetics Department, University of Medicine and Pharmacy 'Victor Babes', Timisoara, Romania; \\ bElias Endocrinology Discipline, 'Carol Davila', University of Medicine and Pharmacy, Bucharest, \\ Romania; 'Endocrinology Department, Elias Hospital, Bucharest, Romania; d Pediatrics Department,

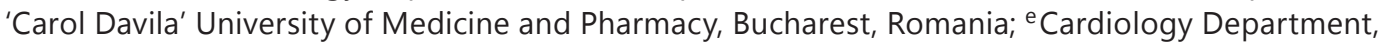 \\ 'Marie Curie' Emergency Children's Hospital Bucharest, Bucharest, Romania; ${ }^{\mathrm{f}}$ Department of \\ Morphological and Functional Sciences, Faculty of Medicine and Pharmacy, 'Dunarea de Jos' \\ University of Galati, Galati, Romania; 9 Pediatrics Department, University of Medicine and Pharmacy \\ 'Victor Babes', Timisoara, Romania; ' ${ }^{2}$ Department of Pathophysiology, Grigore T. Popa University \\ of Medicine and Pharmacy, Iasi, Romania; 'Endocrinology Department, University of Medicine and \\ Pharmacy, Targu Mures, Romania; '3rd Pediatric Clinic, 'Iuliu Hatieganu' University of Medicine and \\ Pharmacy, Cluj-Napoca, Romania; ' ${ }^{k}$ Nephrology Department 'Marie Curie' Emergency Children's \\ Hospital Bucharest, Bucharest, Romania; 'Research Methodology Department, University of \\ Medicine and Pharmacy, Targu Mures, Romania; m Genetics Department, $3^{\text {rd }}$ Pediatric Clinic, \\ Emergency Hospital for Children 'Louis Turcanu', Timisoara, Romania
}

\section{Key Words}

Overweight · Obesity · Romania · Children

\begin{abstract}
Aim: High-quality national representative data on obesity in Romanian children are needed to shape public health policies. To provide a unified data landscape on national prevalence, trends and other factors associated with underweight, overweight, and obesity in Romanian children aged 6-19 years, across the last decade (2006-2015). Methods: Using a common protocol, we selected published and unpublished studies that measured Romanian children in schools between 2006 and 2015. Children's BMI was classified using the current WHO, IOTF, and CDC references. Results: 25,060 children from 8 Romanian counties were included in the analysis. The prevalence of underweight children was 5\%/4.5\%/8.5\% (WHO/IOTF/CDC), while the prevalence of overweight (including obese) children was $28.3 \% / 23 \% / 23.2 \%$ (WHO/IOTF/ CDC). The prevalence of overweight children did not change significantly over the last decade
\end{abstract}


Chirita-Emandi et al.: Overweight and Underweight Prevalence Trends in Children from Romania - Pooled Analysis of Cross-Sectional Studies between 2006 and 2015

(chi-square test $p=0.6$ ). Male gender (odds ratio (OR) 1.37; 95\% CI 1.29-1.45, compared to female); prepubertal age ( $\mathrm{OR}=3.86 ; 95 \%$ CI 3.41-4.36,compared to postpubertal age), and urban environment (OR 1.12; 95\% CI 1.01-1.26, compared to rural environment) had higher risk for overweight. Conclusion: While the prevalence of underweight children was low, almost one in four children in Romania was overweight or obese (according to WHO criteria) between 2006 and 2015. This prevalence remained relatively stable over the last decade. Male gender, prepubertal age, and urban environment, were the most relevant risk factors associated with overweight status in Romanian children.

(C) 2016 The Author(s)

Published by S. Karger GmbH, Freiburg

\section{Introduction}

In adults, overweight and obesity represent a major health burden worldwide due to associated comorbidities such as cardiovascular disease, type 2 diabetes, stroke, cancer and osteoarthritis as well as due to social and psychological problems. Almost one of two adult people in Europe is obese [1]. Excess body weight in children poses a high risk for adult obesity. Research by Guo et al. [2,3] indicated that being overweight at age 35 years may well be predicted from the age of 13 years. Therefore, the prevention of obesity onset should include preventative policies and measures against childhood obesity, especially when considering that weight loss has proven to be extremely difficult $[4,5]$. Moreover, childhood overweight may be associated with immediate negative health outcomes such as high cholesterol [6], high blood pressure [7, 8], prediabetes [9], osteoarticular problems, sleep apnea, and psychological problems such as stigmatization and poor self-esteem [10].

Epidemiologic data provide the rationale for addressing the issue of childhood obesity prevention. In spite of increasing concerns related to childhood obesity, a systematic review comparing estimates of the prevalence of overweight and obesity in school-aged children in 34 nations found many countries lacking high-quality data [11]. There is no study to provide national representative data on obesity in children from Romania. However, several studies on childhood overweight and obesity analyzing representative cohorts at subnational levels have been published in recent years [12-20]. Additionally, very few international reviews or collaborative studies have included Romania in their analyses. A review by Cattaneo et al. [21] included data of pre-schoolers from Romania that had been collected in 2004, reporting a prevalence of overweight plus obesity at age 4 equal to $11.8 \%$. Another study indicated that Romanian children 6-11 years old had the highest prevalence $(31.4 \%)$ of overweight (including obesity) when compared to 7 other European countries [22]. This study used mother-reported heights and weights of children $(n=1,004)$ [22]. The World Health Organization (WHO) European Childhood Obesity Surveillance Initiative (COSI) collection round in 2013 reported an overweight prevalence of $26.8 \%$ (11.6\% for obesity) in 8-year-old children from Romania, using the WHO reference [23], which was among the highest percentages reported in the COSI international samples [24]. Moreover, some underdeveloped or developing countries face a 'double burden' of under- and overnutrition in children and adolescents $[25,26]$.

Undernutrition has not been investigated in a representative cohort from Romania. This pooled analysis of cross-sectional data aims to present, for the first time, national prevalence, trends, and other factors associated with body weight status (overweight, obesity, and underweight) in Romanian children and adolescents for the last decade (2006-2015). 
Chirita-Emandi et al.: Overweight and Underweight Prevalence Trends in Children from

Table 1. Data sources used

\begin{tabular}{|c|c|c|c|c|c|c|c|}
\hline $\begin{array}{l}\text { Year of } \\
\text { assessment }\end{array}$ & County & $\begin{array}{l}\text { Number of } \\
\text { children }\end{array}$ & $\begin{array}{l}\% \text { of total } \\
\text { survived }\end{array}$ & $\begin{array}{l}\text { Number of } \\
\text { children } \\
\text { enrolled in } \\
\text { schools* }\end{array}$ & $\begin{array}{l}\% \text { measured } \\
\text { from all } \\
\text { enrolled* }\end{array}$ & $\begin{array}{l}\text { Age of } \\
\text { children, } \\
\text { years }\end{array}$ & $\begin{array}{l}\text { Reference/author } \\
\text { (for unpublished data) }\end{array}$ \\
\hline 2006 & Bucharest & 2,166 & 8.6 & 265,206 & 0.8 & $6-17$ & [17] \\
\hline 2006 & Ilfov & 2,403 & 9.6 & 39,703 & 6.1 & $6-17$ & [17] \\
\hline 2008 & Cluj & 7,692 & 30.7 & 99,751 & 7.7 & $6-19$ & [13] \\
\hline 2008-2009 & Neamt & 970 & 3.9 & 87,871 & 1.1 & $6-10$ & {$[14]$} \\
\hline 2009-2011 & Dolj & 1,331 & 5.4 & 106,248 & 1.3 & $6-19$ & Gafencu unpublished \\
\hline $2010-2012$ & Iasi & 2,470 & 9.8 & 146,359 & 1.7 & $6-10$ & {$[14]$} \\
\hline 2011 & Bucharest & 861 & 3.4 & 253,894 & 0.3 & $6-18$ & [12] \\
\hline 2011 & Timis & 3,723 & 14.8 & 100,886 & 3.7 & $6-19$ & {$[15,16,46]$} \\
\hline 2013-2014 & Mures & 2,020 & 8.1 & 91,778 & 2.2 & $6-14$ & Pascanu unpublished \\
\hline 2014 & Timis & 332 & 1.3 & 100,327 & 0.3 & $6-19$ & Chirita-Emandi unpublished \\
\hline $2014-2015$ & Galati & 1,092 & 4.4 & 88,046 & 1.2 & $6-19$ & Chesaru unpublished \\
\hline $2006-2015$ & Total & 25,092 & $100 \%$ & $1,380,069$ & 1.8 & $6-19$ & \\
\hline
\end{tabular}

*Total children enrolled in public schools and kindergartens during the study period in each county; data from Romanian National Institute of Statistics [47].

\section{Material and Methods}

\section{Data Sources}

Data sources used, were representative for a population of children from one or multiple Romanian counties and included measurements of height and weight in a school or kindergarten setting. Hospital-based cohort studies were not included. Self-reported data on height and weight were not used because these are subject to significant biases that are influenced by geographic area, age, sex, and socioeconomic characteristics such as education and ethnicity $[27,28]$.

Multiple methods for identifying and accessing data were used. MEDLINE and Google Scholar searches identified published studies that measured the variables of interest in Romanian public school and kindergarten children. The search included the combination of the following terms (in Romanian and English): obesity, overweight, body fat, body weight, or body mass index and children or school and Romania. Thus, eight data sources were identified. The authors of these studies were contacted and asked to provide the raw, anonymized individual record data according to a common protocol. Five out of the eight identified sources provided the requested data. Additionally, the authors were asked if they had knowledge of other unpublished data sources. With this approach, another five data sources with suitable study design were identified of which four also provided the data. Before calculating means and prevalence, participants younger than 6 years and older than 19 years were excluded. Participants with BMI considered implausible were excluded (below $-6 \mathrm{SD}$ or above $+6 \mathrm{SD}$ ). Information was provided about the study population, period of measurement, sampling approach, and measurement. Data sources used are listed in table 1 (11 cohorts from 9 studies).

\section{Data Collection}

For the studies included in this article, random sampling methods for each county were applied to obtain selected schools and kindergartens where the measurements were performed. The sampled schools and kindergartens included in this study were assessed between 2006 and 2015. All included studies were cross-sectional. Two studies included data from the same counties at multiple time points (Timis and Bucharest), obtained several years apart. However, the included schools and kindergartens were different; therefore, the likelihood of measuring the same children at different time points was very small. All anthro- 
Chirita-Emandi et al.: Overweight and Underweight Prevalence Trends in Children from

Romania - Pooled Analysis of Cross-Sectional Studies between 2006 and 2015

pometric data were collected by physicians, school nurses, or medical students. All examiners were trained in taking accurate measurements according to international measurement techniques. Each child underwent anthropometric assessments that were carried out during one-day sessions. Height and body mass was obtained using calibrated scales. The subjects wore normal, light, indoor clothing without shoes. BMI was calculated as weight $(\mathrm{kg})$ divided by squared height $\left(\mathrm{m}^{2}\right)$.

\section{Definitions}

To enable comparison with other studies we used three different criteria panels to classify BMI in children.

The WHO 2007 BMI reference criteria for age and gender in children 5-19 years [29] classify children's BMI using standard deviations (SD) as follows: overweight: >1 SD (equivalent to BMI $25 \mathrm{~kg} / \mathrm{m}^{2}$ at 19 years); obese: >2 SD (equivalent to BMI $30 \mathrm{~kg} / \mathrm{m}^{2}$ at 19 years); severely obese: >3 SD; thin: <-2 SD; severely thin: $<-3$ SD.

Considering the International Obesity Task Force revised references (IOTF, Cole 2012) [30], the BMI cut-offs at 18 years were: thinness $<17 \mathrm{~kg} / \mathrm{m}^{2}$ (includes thinness grades 2 and 3); overweight $\geq 25 \mathrm{~kg} / \mathrm{m}^{2}$, obese $\geq 30 \mathrm{~kg} / \mathrm{m}^{2}$; morbidly obese $\geq 35 \mathrm{~kg} / \mathrm{m}^{2}$ [30]. For this study, thinness grade 1 (defined by the cut-off $\mathrm{BMI}<18.5 \mathrm{~kg} / \mathrm{m}^{2}$ at age 18 years), was included in the 'normal' category, in order to enable appropriate comparisons with the other references used.

The Centers for Disease Control and Prevention (CDC) reference (2000) for children and adolescents aged 2-20 years, were used to classify children's BMI as: 'overweight' if BMI was between the 85th and 95th percentiles and 'obese' if BMI was above the 95th percentile, while 'underweight' was considered if BMI was $<5$ th percentile for specific age and gender [31].

In this study, the term 'underweight' encompassed thinness and severe thinness together, while 'excess weight' summarized overweight, obese and severely obese children altogether.

The children were classified according to their age as being prepubertal (6-9years old), in early puberty (10-12 years old), in middle puberty (13-14 years old), in late puberty (15-16 years old) and postpubertal (17-19 years old).

In order to assess a possible socioeconomic impact on children's BMI status, we used the Human Development Index (HDI) yearly values reported for Romania by Human Development Report Office for the United Nations Development Program [32]. HDI incorporates the level of socioeconomic development of a country by combining three indicators: income per capita, literacy rate, and life expectancy.

\section{Ethical Considerations}

Two methods were used for obtaining informed consent from the participants in the selected studies. The first method used by all data sources, except for the one in Timis (2011) [15], consisted of each participating child being required to obtain written, informed consent from his or her legal guardian. The second method used a 'passive consent' or 'opt out' method, where parents were fully informed about all study procedures through a school information meeting [15]. Parents who refused the participation communicated this to the school principal. In all studies, prior to enrolment, the children also gave their assent to participate. All data sources came from studies that were approved by the Institutional Ethical Advisory Board of the respective research organization or University, in accordance with the Declaration of Helsinki.

\section{Statistical Analysis}

Descriptive statistics are outlined for all variables assessed as mean and standard deviation (SD) for continuous variables and as percentages for categorical variables. The Student's t test was used for evaluating differences between groups of continuous variables. Pearson's chi-square test was used to evaluate differences between groups for categorized variables. Multinominal multivariate logistic regression was used to examine the combined effects of year of assessment, gender, environment, pubertal age, and county as predictors of underweight and excess weight. Statistical significance was reported at $\mathrm{p}<0.05$. Data were analyzed with SPSS 
Chirita-Emandi et al.: Overweight and Underweight Prevalence Trends in Children from Romania - Pooled Analysis of Cross-Sectional Studies between 2006 and 2015

Table 2. Mean and standard deviations for age and BMI SDS using the WHO reference for each county and each gender

\begin{tabular}{|c|c|c|c|c|c|c|c|c|c|c|}
\hline \multirow[t]{3}{*}{ County } & \multicolumn{3}{|l|}{ All } & \multicolumn{3}{|l|}{ Male } & \multicolumn{3}{|l|}{ Female } & \multirow{3}{*}{$\begin{array}{l}\text { p value } \\
\text { (male/ } \\
\text {-female) }\end{array}$} \\
\hline & \multirow[t]{2}{*}{$\mathrm{N}$} & \multicolumn{2}{|c|}{ age, years } & \multirow[t]{2}{*}{$\mathrm{N}$} & \multicolumn{2}{|c|}{ age, years } & \multirow[t]{2}{*}{$\mathrm{N}$} & \multicolumn{2}{|c|}{ age, years } & \\
\hline & & mean & SD & & mean & SD & & mean & SD & \\
\hline Bucharest & 3,027 & 10.98 & 2.72 & 1,464 & 11.23 & 2.77 & 1,563 & 10.74 & 2.66 & $<0.001$ \\
\hline Cluj & 7,692 & 12.78 & 3.60 & 3,776 & 12.70 & 3.48 & 3,916 & 12.85 & 3.71 & 0.066 \\
\hline Dolj & 1,331 & 12.77 & 3.59 & 693 & 12.38 & 3.69 & 638 & 12.00 & 3.57 & 0.061 \\
\hline Galati & 1,092 & 14.26 & 3.77 & 568 & 14.20 & 3.73 & 524 & 14.33 & 3.83 & 0.584 \\
\hline Iasi & 2,470 & 7.68 & 1.27 & 1,264 & 7.71 & 1.28 & 1,206 & 7.66 & 1.25 & 0.379 \\
\hline Ilfov & 2,403 & 11.26 & 3.46 & 1,216 & 11.19 & 3.44 & 1,187 & 11.32 & 3.48 & 0.351 \\
\hline Mures & 2,020 & 10.59 & 2.43 & 989 & 10.47 & 2.38 & 1,031 & 10.71 & 2.48 & 0.026 \\
\hline Neamt & 970 & 8.51 & 1.22 & 466 & 8.50 & 1.22 & 504 & 8.51 & 1.22 & 0.923 \\
\hline Timis & 4,055 & 12.60 & 3.21 & 1,771 & 12.13 & 3.01 & 2,284 & 12.97 & 3.32 & $<0.001$ \\
\hline All & 25,092 & 11.56 & 3.56 & 12,222 & 11.48 & 3.48 & 12,870 & 11.65 & 3.63 & $<0.001$ \\
\hline \multirow[t]{3}{*}{ County } & \multicolumn{3}{|l|}{ All } & \multicolumn{3}{|l|}{ Male } & \multicolumn{3}{|l|}{ Female } & $\mathrm{p}$ value \\
\hline & \multirow[t]{2}{*}{$\mathrm{N}$} & \multicolumn{2}{|c|}{ BMI SDS } & \multirow[t]{2}{*}{$\mathrm{N}$} & \multicolumn{2}{|c|}{ BMI SDS } & \multirow[t]{2}{*}{$\mathrm{N}$} & \multicolumn{2}{|c|}{ BMI SDS } & $\begin{array}{l}\text { (male/ } \\
\text { female) }\end{array}$ \\
\hline & & mean & SD & & mean & SD & & mean & SD & \\
\hline Bucharest & 3,027 & 0.31 & 1.63 & 1,464 & 0.32 & 1.74 & 1,563 & 0.29 & 1.52 & 0.636 \\
\hline Cluj & 7,692 & 0.29 & 1.26 & 3,776 & 0.41 & 1.31 & 3,916 & 0.16 & 1.19 & $<0.001$ \\
\hline Dolj & 1,331 & 0.04 & 1.22 & 693 & 0.11 & 1.26 & 638 & -0.04 & 1.17 & 0.029 \\
\hline Galati & 1,092 & 0.05 & 1.26 & 568 & 0.21 & 1.31 & 524 & -0.12 & 1.18 & $<0.001$ \\
\hline Iasi & 2,470 & 0.31 & 1.40 & 1,264 & 0.23 & 1.54 & 1,206 & 0.40 & 1.23 & 0.002 \\
\hline Ilfov & 2,403 & -0.14 & 1.36 & 1,216 & -0.12 & 1.42 & 1,187 & -0.17 & 1.29 & 0.376 \\
\hline Mures & 2,020 & -0.02 & 1.79 & 989 & 0.10 & 1.82 & 1,031 & -0.14 & 1.76 & 0.003 \\
\hline Neamt & 970 & 0.47 & 1.37 & 466 & 0.42 & 1.46 & 504 & 0.52 & 1.28 & 0.238 \\
\hline Timis & 4,055 & 0.39 & 1.35 & 1,771 & 0.60 & 1.42 & 2,284 & 0.23 & 1.26 & $<0.001$ \\
\hline All & 25,092 & 0.23 & 1.41 & 12,222 & 0.31 & 1.48 & 12,870 & 0.15 & 1.32 & $<0.001$ \\
\hline
\end{tabular}

BMI SDS = BMI Standard deviation Z score

20 (SPSS Inc, Chicago, IL, USA). To analyze the BMI classification for children, we used an application tool provided by the WHO - a macro for SPSS that has been described elsewhere [33]. For classifying BMI according to the CDC criteria, we used the commercial software EZ BMI Calculator [34]. For classifying BMI using the IOTF revised cut-offs, a script was created (in Phyton programming language) using the cut-off values provided by Cole et al. [30]. This script is available at https://github.com/dragulescubogdan/COFFS.

\section{Results}

\section{Description of Participants}

Complete data were received from 25,768 participants in the selected studies, of which 394 individuals were younger than 6 years, 251 individuals were older than 19 years, and 95 children were considered to have improbable BMI (above +6 SD or below -6 SD), when using the WHO reference criteria. Thus, 25,060 children from 8 Romanian counties were 


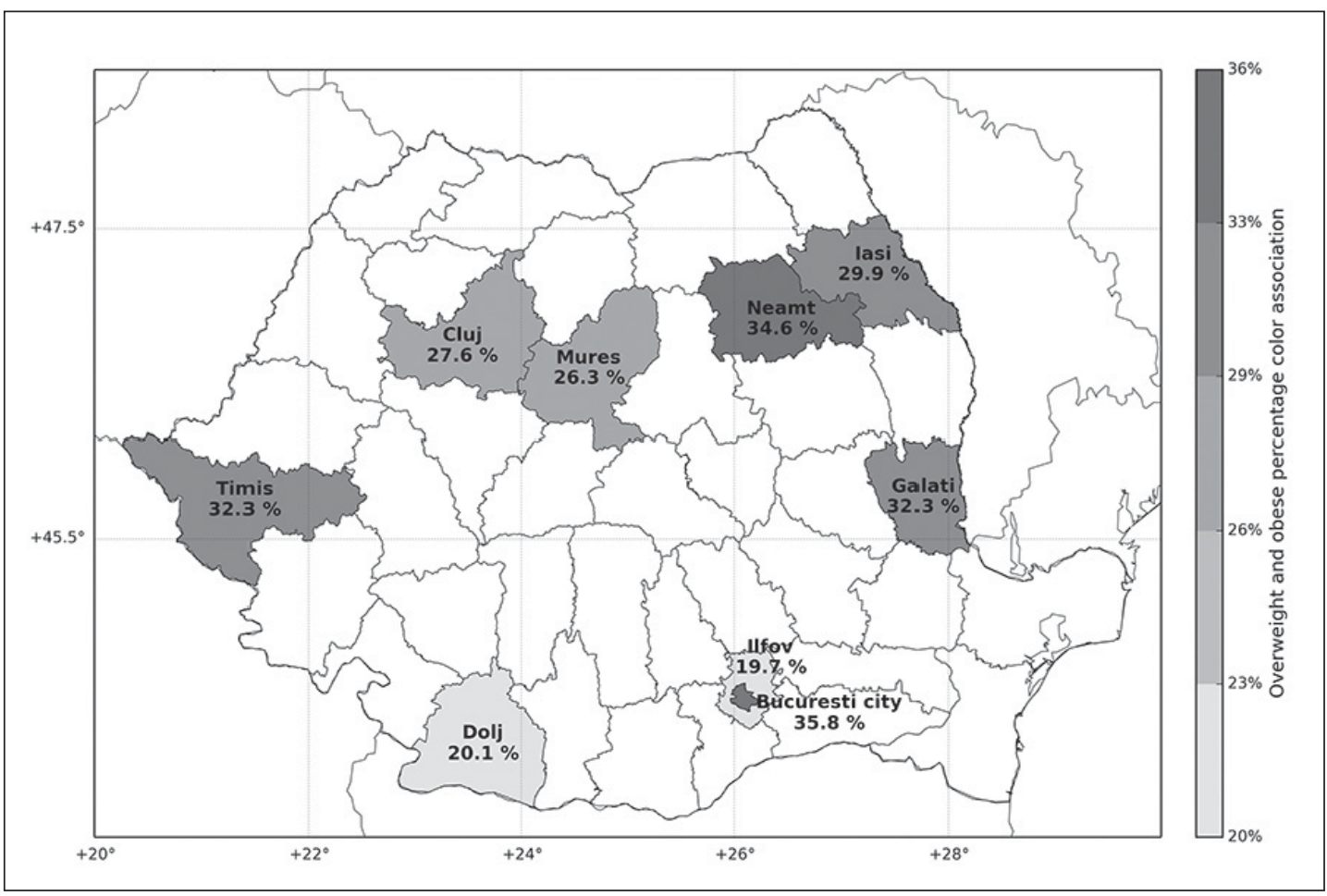

Fig. 1. Map of Romania with percentage of children with excess weight (overweight including obesity WHO) per county - averaged over a decade (2006-2015). Data were available for shaded counties.

included in the analysis, of which $48.7 \%$ were males and $51.3 \%$ were females. Most of the participating children were from the urban environment $(80.4 \%)$, and only $19.6 \%$ were from rural areas. The numbers, means \pm SD for age (years) and BMI SDS values using WHO reference are presented in table 2 for all participating children and separately for males and females.

Prevalence of Underweight, Overweight, and Obesity in Romania, Using WHO, IOTF, and CDC References

Overall, in the last decade, in Romanian 6- to 19-year-old children, the prevalence of underweight status was 5\% (WHO), 4.5\% (IOTF), or 8.5\% (CDC) (table 3), while the prevalence of overweight status (including obesity) was 28.3\% (WHO), 23\% (IOTF), or 23.2\% (CDC). The prevalence of underweight, overweight and obese participants using age and sex stratification is also presented in table 3.

Children included in this analysis were recruited from eight Romanian counties covering all four macro-regions in the country, including Bucharest (2.1 million inhabitants, the capital of Romania), and the other two counties with high population density and higher economic development as well as less populated and less developed counties. Prevalence of excess weight (WHO) in children aged 6 to 19 years is presented in figure 1 for each participating county. 
Chirita-Emandi et al.: Overweight and Underweight Prevalence Trends in Children from Romania - Pooled Analysis of Cross-Sectional Studies between 2006 and 2015

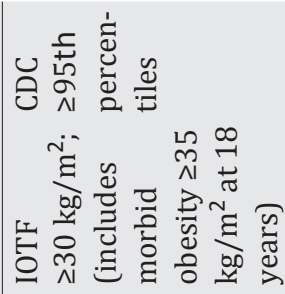

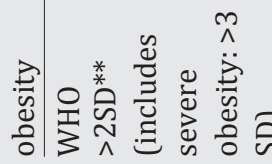

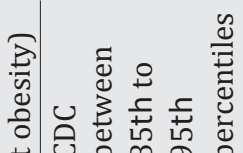

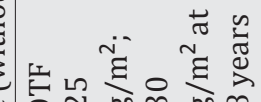

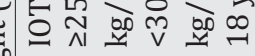
3월

वा $\$ त

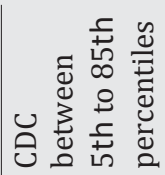
ฮี $\pi$ 氜地

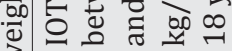
वृ के क

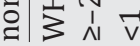

|

N छ)

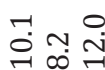
นุํ กู ติ

$\stackrel{ }{\vec{G}}$ 늉

농 $\underset{m}{\rightarrow} \stackrel{m}{\rightarrow}$

느 두웅 它守

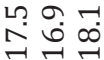

m. 느 田

ᄂก $\infty$ 둔

iñ

0.0 는 ठำ

$\infty$ 둥요

낭 앙 웅

من

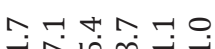

تำ

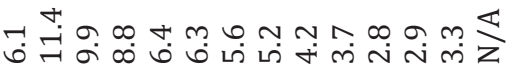

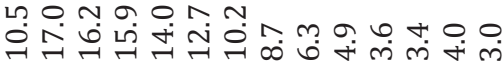

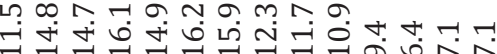

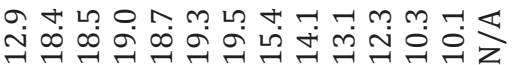

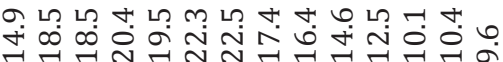

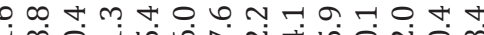
ชิ

a

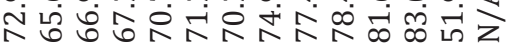

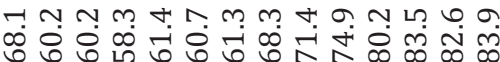

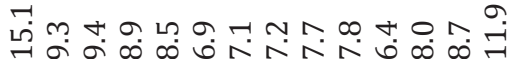

م

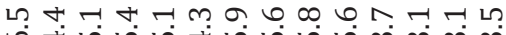

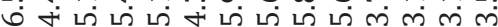

mª

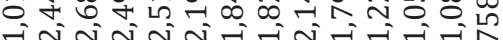
苋

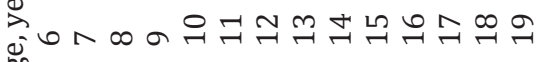


Fig. 2. Percentages of overweight, obesity and severe obesity in children (WHO) in each year from 2006 to 2015 and corresponding HDI values (where available).

Chirita-Emandi et al.: Overweight and Underweight Prevalence Trends in Children from Romania - Pooled Analysis of Cross-Sectional Studies between 2006 and 2015

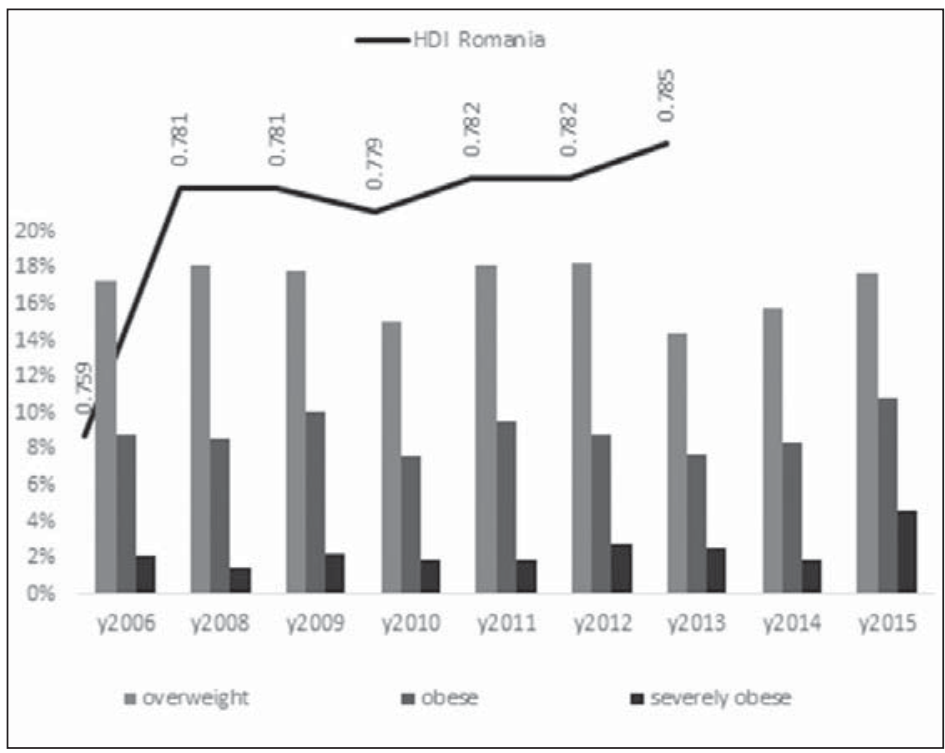

Trends of Overweight and Underweight Prevalence over the Last Decade in Romania

No significant trend for overweight prevalence was observed over the years of the last decade (chi-square test $\mathrm{p}=0.609$ for all years). However, the prevalence of excess weight (WHO) peaked in 2009 (30.1\%), 2012 (29.8\%) and 2015 (33.2\%) The lowest prevalence was observed in 2010 (24.5\%) and 2013 (24.6\%) (fig. 2). The dips of excess weight prevalence coincided with a decrease in HDI in the same year. However, the data are cross sectional and measured in different counties and in different years; thus the variation could be attributed to regional characteristics. Data sources collected in the same county several years apart were available for Bucharest city and Timis county, as previously mentioned. In Bucharest city, the prevalence of excess weight was $37.3 \%$ in 2006 and $31.9 \%$ in 2011 ( $p<0.001$ ), while in Timis County it was $31 \%$ in 2011 and $37.7 \%$ in 2014 ( $p=0.027)$. We found a weak but statistically significant Spearman correlation between HDI and BMI SDs ( $r=0.028, p<0.001)$.

Conversely, prevalence of underweight was higher in 2006 (8.9\%), and 2013 (13.3\%); and lower in 2008 (2.7\%) and 2014 (3.3\%).

\section{Factors Associated with Overweight Prevalence (WHO Reference) in Romanian Children}

Prevalence of excess weight children (WHO) was higher in urban $(29.5 \%=18.3 \%$ overweight $+11.2 \%$ obese; $n=20,137)$ versus rural environment $(22.9 \%=14 \%$ overweight + $9.9 \%$ obese; $n=4,923)(p<0.001)$. A significant difference was maintained in both males and females when stratifying by sex. $33.2 \%$ of males from urban environment had excess weight and $4.5 \%$ were underweight, compared to $23.5 \%$ and $8.6 \%$, respectively, in the rural environment ( $\mathrm{p}<0.001$ ). Of the females from urban environment, $26.1 \%$ had excess weight, while $4 \%$ were underweight, whereas in the rural environment the values amounted to $22.4 \%$ or $7.1 \%(\mathrm{p}<0.001)$.

The prevalence of underweight children (WHO thin + severely thin) remained relatively stable throughout all ages (average 5\%), ranging from 3.1\% in postpubertal youths to 5.7\% in middle puberty $(\mathrm{p}<0.001)$. In contrast, the percentage of children with excess weight 
Chirita-Emandi et al:: Overweight and Underweight Prevalence Trends in Children from Romania - Pooled Analysis of Cross-Sectional Studies between 2006 and 2015

Table 4. Odds ratio for each variable from a multinominal logistic regression model of predictors (assessment year, gender, pubertal age, and environment) underweight and excess weight compared to normal weight (reference) in children and adolescents

\begin{tabular}{|c|c|c|}
\hline \multirow[t]{2}{*}{ Items } & \multicolumn{2}{|l|}{ OR $(95 \% \mathrm{CI})$} \\
\hline & $\begin{array}{l}\text { underweight <-2 BMI SD } \\
\text { (WHO) }\end{array}$ & $\begin{array}{l}\text { excess weight }>1 \text { BMI SD } \\
(\mathrm{WHO})\end{array}$ \\
\hline Assessment year & $0.74(0.68 ; 0.79)$ & $0.96(0.93 ; 0.99)$ \\
\hline \multicolumn{3}{|l|}{ Gender } \\
\hline male & $1.28(1.13 ; 1.44)$ & $1.37(1.29 ; 1.45)$ \\
\hline female (used as reference) & 1 & 1 \\
\hline \multicolumn{3}{|l|}{ Pubertal age } \\
\hline Prepubertal (6-9 years) & $1.50(1.17 ; 1.94)$ & $3.86(3.41 ; 4.36)$ \\
\hline Early puberty (10-12 years) & $1.37(1.06 ; 1.76)$ & $3.41(3.02 ; 3.86)$ \\
\hline Middle puberty (13-14 years) & $1.40(1.07 ; 1.81)$ & $2.08(1.82 ; 2.38)$ \\
\hline Late puberty (15-16 years) & $1.32(1.01 ; 1.75)$ & $1.42(1.23 ; 1.64)$ \\
\hline Postpubertal (17-19 years)(used as reference) & 1 & 1 \\
\hline \multicolumn{3}{|l|}{ Environment } \\
\hline Urban & $0.77(0.62 ; 0.94)$ & $1.12(1.01 ; 1.26)$ \\
\hline Rural (used as reference) & 1 & 1 \\
\hline \multicolumn{3}{|l|}{ County } \\
\hline Bucharest & $0.65^{*}(0.42 ; 1.01)$ & $0.88 *(0.74 ; 1.03)$ \\
\hline Cluj & $0.27(0.20 ; 0.39)$ & $0.70(0.61 ; 0.80)$ \\
\hline Dolj & $0.67(0.48 ; 0.94)$ & $0.49(0.42 ; 0.57)$ \\
\hline Galati & $1.75(1.15 ; 2.56)$ & $0.87 *(0.73 ; 1.05)$ \\
\hline Iasi & $1.27^{*}(0.95 ; 1.69)$ & $0.57(0.50 ; 0.65)$ \\
\hline Ilfov & $0.32(0.20 ; 0.52)$ & $0.41(0.33 ; 0.51)$ \\
\hline Neamt & $0.36(0.23 ; 1.59)$ & $0.64(0.53 ; 0.76)$ \\
\hline Targu Mures & $1.48(1.08 ; 2.39)$ & $0.76(0.65 ; 0.87)$ \\
\hline Timis & 1 & 1 \\
\hline
\end{tabular}

The intercept of the multinominal multivariate logistic regression model was $2,429.2, \mathrm{p}<0.001$.

*Not significant.

(overweight + obese + severely obese) changed dramatically over different ages. On average, $28.3 \%$ of children, aged 6-19 years, presented excess weight. Highest percentages of excess weight were observed in prepubertal children (34.2\%) and early puberty (33.8\%), while lowest percentages were observed in late puberty (18.1\%) and postpubertal youths $(13.6 \%)$ ( $\mathrm{p}<0.001$ ) (see supplemental fig. S1; available at http://content.karger.com/ProdukteDB/ produkte.asp?doi=444173). A significant difference between pubertal ages is maintained when controlling for gender (chi-square test $\mathrm{p}<0.001$ ), as shown below.

On average, $25.4 \%$ of females aged $6-19$ years had excess weight, and $4.6 \%$ were underweight (WHO). Highest percentages of excess weight were observed in prepubertal females $(33.5 \%)$ and early puberty (30.5\%), while lowest percentages were observed in late puberty $(12.4 \%)$ and postpubertal females (10.0\%) (see supplemental fig. S2; available at $h t t p: / /$ content.karger.com/ProdukteDB/produkte.asp?doi=444173)

In males aged 6-19 years, $31.2 \%$ had excess weight, and 5.3\% were underweight (WHO). Highest percentages of excess weight were observed in prepubertal males (34.8\%), and in early puberty (37.1\%), while the lowest prevalence was observed in postpubertal males (18.4\%) (see supplemental fig. S3; available at http://content.karger.com/ProdukteDB/ produkte.asp?doi=444173). 
Chirita-Emandi et al.: Overweight and Underweight Prevalence Trends in Children from Romania - Pooled Analysis of Cross-Sectional Studies between 2006 and 2015

Bivariate associations between assessment year, birth year, pubertal age, gender, environment or county and underweight or excess weight (WHO) as main effects were tested, then significant associations were included in a multinominal multivariate logistic regression model (table 4). Birth year was not included in the model as it was not significantly associated with underweight or excess weight. The assessment year was negatively correlated with underweight $(\mathrm{OR}=0.74,95 \% \mathrm{CI}=0.68-0.79)$, and with overweight - including obesity $(\mathrm{OR}=0.96 ; 95 \% \mathrm{CI}=0.93-0.99)$, when using year 2006 as reference. Male gender associated with both increased risk for being underweight $(O R=1.28,95 \% \mathrm{CI}=1.13-1.44)$ and overweight $(\mathrm{OR}=1.37,95 \% \mathrm{CI}=1.29-1.45)$, when compared to females. Prepubertal age increased the risk for being underweight $(\mathrm{OR}=1.50,95 \% \mathrm{CI}=1.17-1.94)$, and even more for the risk of being overweight $(\mathrm{OR}=3.86,95 \% \mathrm{CI}=3.41-4.36)$, when compared to postpubertal age. The urban environment decreased the risk for being underweight (OR $=0.77,95 \%$ $\mathrm{CI}=0.62-0.94)$, while it increased the risk for being overweight $(\mathrm{OR}=1.12,95 \% \mathrm{CI}=1.01$ 1.26), when compared to rural environment. The region (county) had a significant but relatively minor effect on the risk for underweight and excess weight in several counties, as shown in table 4.

\section{Discussion}

For the first time, to our knowledge, this study presented epidemiologic data on excess weight and underweight in the last decade (2006-2015) with national representation for Romanian children aged 6-19 years. A large number of children $(25,060)$ from 8 Romanian counties were included in the analysis. Prevalence for excess weight and underweight was determined using the WHO, the IOTF and the CDC reference criteria sets to enable comparison with other studies. As such, these different criteria used to classify BMI generated different prevalence rates. IOTF criteria provided lower rates of overweight and obesity, when compared to $\mathrm{WHO}$ and $\mathrm{CDC}$ criteria, and these findings align with similar differences as already published $[24,30,35,36]$.

\section{Excess Weight}

\section{Prevalence of Excess Weight - Comparisons with Other Countries}

Excess weight in 6- to 19-year-old Romanian children was found in $28.3 \%$ (WHO reference) [29]; 23\% (IOTF cut-offs) [30] and 23.2\% (CDC reference) [31]. A comparison between different references is subject of several other studies, but this is beyond the scope of this paper. The prevalence of excess weight in Romanian children aged 6-9 years was on average 35\% (WHO reference) in this study. The value is similar to those from countries such as Slovenia, Portugal or Spain, as assessed by the COSI study (WHO reference) [24]. The World Health Organization (COSI) included 2,800 children from Romania that were measured in 2013. The reported prevalence of overweight was $26.8 \%$ (11.6\% for obesity) in 8-year-old children from Romania using the WHO reference [23]. In our study, we found a prevalence of $34.7 \%$ for overweight $(16.2 \%$ for obesity) in 8 -year-olds $(n=2,688)$. The difference could be explained by the fact that our sample included more children form the urban environment, while the COSI report indicated rates of $31.4 \%$ for overweight children in urban environment, as compared to $21.6 \%$ in rural. Additionally our data represents an average across the last decade. The prevalence for excess weight reported by the ENERGY project in Romanian children at the age 10-12 years was 34\% and thus similar to that in Hungary, Slovenia, and Spain (WHO reference) [37]. Although the prevalence of overweight children was slightly 
Chirita-Emandi et al.: Overweight and Underweight Prevalence Trends in Children from Romania - Pooled Analysis of Cross-Sectional Studies between 2006 and 2015

lower in Romania as compared to other countries such as Italy or Greece [24, 37], these findings are worrisome and provide the rationale for devising and implementing further prevention strategies.

\section{Trends in Overweight Prevalence over the Last Decade in Romania}

In the last 20 years, Romania went through important political and economic transition stages and sociodemographic changes that might have influenced nutritional patterns [38]. However, a significant trend over the years in the last decade (2006-2015) was not observed in our study. Two peaks were noticed for 2009 and 2015, while two dips were found for 2010 and 2013 that coincided with a decrease in HDI. Only a very weak positive correlation between BMI SDS and HDI was found. A detailed analysis in the two counties (Bucharest and Timis) where measurements were performed several years apart, showed a peak in 2006-2009 and a dip in 2014-2015. The relation between trends of overweight prevalence and HDI as a marker of socioeconomic status must be interpreted with caution, as individual data related to socioeconomic status of the family were not available for this study.

\section{Gender Differences in Overweight Prevalence in Romania}

In Romania, boys were 1.4 times more likely to have excess weight when compared to girls. The COSI study 2013 collection round in Romania also indicated that 8-year-old boys had a higher prevalence of overweight and obesity (29.8\%) when compared to girls $(23.7 \%)$ [23]. A higher prevalence of overweight in boys was also found in several other European countries such as Slovenia, Spain, Italy, Greece, or Hungary [37]. The same study indicated that potential risk behaviors for excess weight are generally more likely in children of parents with fewer years of formal education. Thus, interventions aiming to prevent overweight and obesity in school-aged children should pay specific attention to boys and children of loweducated parents [37].

\section{Overweight Prevalence in Regards to Environment}

Excess weight was more prevalent in the urban than in the rural environment (OR $=1.12$; $95 \% \mathrm{CI}=1.01-1.26)$. Similar findings were reported by the COSI study in Romania [23] and by studies in East Slovakia and Poland [39, 40], but not by others in Greece [41] or the USA [42]. This variation may be attributed to differences related to education, physical activity, sedentary behavior, economical family status, or even self-perception [41, 42].

The different regions in Romania included in the pooled analysis had a minor impact on excess weight prevalence. This finding may reflect the different economic status throughout the counties; however, more studies are needed to identify the causes of this outcome.

\section{Overweight Prevalence Variation in Regards to Children's Age in Romania}

The percentage of children with excess weight changed dramatically in children of different ages. The highest percentages (average 34\%) of excess weight were observed in 6to 12-year-olds (prepubertal and in early puberty), while the prevalence decreased to less than half in 15- to 19-year-olds (late puberty and postpubertal youths). The logistic regression indicated that prepubertal and early pubertal children were 3.9 times more likely to have excess weight as compared to postpubertal youths. The variation was maintained after stratifying by gender, albeit with lower values for females as compared to males. Other studies have also found higher prevalences in pre- and early adolescence $[43,44]$. Weight gain before puberty promotes earlier initiation of the maturation process mediated by luteinizing hormone concentrations in girls [45]. Therefore, there is a urgent need for early interventions in pre-adolescent years, in both genders, in Romanian children. 
Chirita-Emandi et al.: Overweight and Underweight Prevalence Trends in Children from Romania - Pooled Analysis of Cross-Sectional Studies between 2006 and 2015

\section{Underweight}

The prevalence of children aged 6-19 years that were underweight (below -2 BMI SDS using the WHO reference) was low in Romania, with an average of $5 \%$. The logistic regression showed a slightly negative trend from 2006 to 2015. In detail, males had a higher prevalence of underweight as compared to females (5.3\% vs. 4.6\%). Both males and females from rural environment had higher prevalence of underweight when compared to urban participants. The relatively low levels of underweight children in Romania could be explained by the capitalist economy, which is promoting a consumption-driven behavior, inducing widespread overnutrition. In Romania, prepubertal and early pubertal children were 1.5 times more likely to be underweight, as compared to postpubertal participants, indicating that the peripubertal age needs to be under healthcare surveillance for both risks of under- and overnutrition.

\section{Study Limitations}

This study has severallimitations. The study included more children from urban compared to rural environment. The study did not assess, nor adjusted, for factors such as dietary factors, birth weight, breastfeeding, food security, maternal and childcare, health services, and other environmental factors that could influence growth. Puberty has major implication upon growth and development, but in our study, Tanner stage was not assessed due to methodological and ethical issues. However, some insights are provided by assessing the data set in accordance to age groups known to be associated to a certain pubertal stage. Socioeconomic information about children's families was not available.

\section{Conclusion}

Overall, according to the WHO reference, in Romania almost one in four children aged 6-19 years was overweight or obese between 2006 and 2015. This prevalence remained relatively stable over the years during the last decade. Prepubertal age, urban environment, and male gender were variables associated with increased risk for excess weight in Romanian children. The prevalence of underweight in Romania was low, affecting more females, preadolescent children, and those from rural environment. This study indicated that a significant part of children in Romania are either underweight or overweight. The prevalence of overweight and obese children is at levels comparable with those from other European countries, which includes Romania among the countries in which childhood obesity is at epidemic levels. Therefore, this study reinforces the need for a comprehensive approach in the fight against childhood obesity and for the implementation of public health policies for the prevention of the obesity epidemic.

\section{Acknowledgements}

We thank Bogdan Dragulescu from Politehnica University of Timișoara for rendering the vector map of Romania and designing a script (Phyton programming language) that uses the revised IOTF cut-offs to calculate prevalence of Thinness, Overweight and Obesity in Children. We thank Dr. Mihai Niculescu (The University of North Carolina at Chapel Hill) for critical appraisal of the manuscript and proofreading. We also acknowledge Silvia Mandasescu (Roman Municipal Hospital), Lecturer Cornel Vălean and Prof. Mircea Nanulescu (Clinical Emergency Hospital for Children Cluj) for their involvement in data collection. 
Chirita-Emandi et al.: Overweight and Underweight Prevalence Trends in Children from

Romania - Pooled Analysis of Cross-Sectional Studies between 2006 and 2015

\section{Funding}

Adela Chirita-Emandi was funded through a project for young researchers: Internal Competition University of Medicine and Pharmacy 'Victor Babes' Timisoara, Program II-C4-TC-2016. Pascanu M. Ionela and Raluca Pop were supported by an internal research grant from University of Medicine and Pharmacy Targu-Mures, Romania (Nr. 17802/1/22.12.2015). Maria Puiu was funded under operational program: Development of Existing Infrastructure and Creation of New Infrastructure (Laboratories, Research Centers) POSCCE-A2-02.2.1-2013-1, in the Center of Genomic Medicine of the University of Medicine and Pharmacy 'Victor Babes' Timisoara. These funders had no role in study design, data collection and analysis, decision to publish, or preparation of the manuscript. All other authors received no specific funding for this work.

\section{Contributor's Statement}

Adela Chirita-Emandi performed part of initial data collection, designed the study plan, coordinated and supervised data collection from all data sources, performed the statistical analysis, drafted the initial manuscript, revised the manuscript, and approved the final manuscript as submitted.

Carmen Gabriela Barbu, Eliza Cinteza, Bianca Ioana Chesaru, Michaela Dobre, Simona Vasilica Fica, Mihai Gafencu, Gabriela Edita Ichim, Veronica Mocanu, Ionela M. Pascanu, Raluca Pop, Simona Alexandra Tatar, each contributed, in part, to initial data collection, reviewed and revised the manuscript, and approved the final manuscript as submitted.

Maria Puiu conceptualized the study, performed part of initial data collection, supervised data collection, critically reviewed the manuscript, and approved the final manuscript as submitted.

\section{Disclosure Statement}

All authors have no conflict of interest to declare.

\section{References}

1 Gallus S, Lugo A, Murisic B, Bosetti C, Boffetta P, La Vecchia C: Overweight and obesity in 16 European countries. Eur J Nutr 2015;54:679-689.

2 Guo, Chumlea: Tracking of body mass index in children in relation to overweight in adulthood. Am J Clin Nutr 1999;70:145S-148S.

3 Guo SS, Wu W, Chumlea WC, Roche AF: Predicting overweight and obesity in adulthood from body mass index values in childhood and adolescence. Am J Clin Nutr 2002;76:653-658.

4 Dombrowski SU, Knittle K, Avenell A, Araújo-Soares V, Sniehotta FF: Long term maintenance of weight loss with non-surgical interventions in obese adults: systematic review and meta-analyses of randomised controlled trials. BMJ 2014;348:g2646.

5 Golomb I, Ben David M, Glass A, Kolitz T, Keidar A: Long-term metabolic effects of laparoscopic sleeve gastrectomy. JAMA Surg;150:1051-1057.

6 van Vliet M, Heymans MW, von Rosenstiel IA, Brandjes DPM, Beijnen JH, Diamant M: Cardiometabolic risk variables in overweight and obese children: a worldwide comparison. Cardiovasc Diabetol 2011;10:106.

7 Freedman DS, Mei Z, Srinivasan SR, Berenson GS, Dietz WH: Cardiovascular risk factors and excess adiposity among overweight children and adolescents: the Bogalusa Heart Study. J Pediatr 2007;150:12-17.e2.

8 Sypniewska G: Laboratory assessment of cardiometabolic risk in overweight and obese children. Clin Biochem 2015;48:370-376.

9 Ali O, Cerjak D, Kent JW, James R, Blangero J, Zhang Y: Obesity, central adiposity and cardiometabolic risk factors in children and adolescents: a family-based study. Pediatr Obes 2014;9:e58-62.

10 Herget S, Rudolph A, Hilbert A, Blüher S: Psychosocial status and mental health in adolescents before and after bariatric surgery: a systematic literature review. Obes Facts 2014;7:233-245.

11 Janssen I, Katzmarzyk PT, Boyce WF, Vereecken C, Mulvihill C, Roberts C, et al: Comparison of overweight and obesity prevalence in school-aged youth from 34 countries and their relationships with physical activity and dietary patterns. Obes Rev 2005;6:123-132.

12 Barbu CG, Teleman MD, Albu AI, Sirbu AE, Martin SC, Bancescu A, et al: Obesity and eating behaviors in school children and adolescents -data from a cross sectional study from Bucharest, Romania. BMC Public Health 2015; 15:206. 
Chirita-Emandi et al.: Overweight and Underweight Prevalence Trends in Children from

Romania - Pooled Analysis of Cross-Sectional Studies between 2006 and 2015

13 Valean C, Tatar S, Nanulescu M, Leucuta A, Ichim GC: Prevalence of obesity and overweight among school children in Cluj-Napoca. Acta Endocrinologica (Buc) 2009;5:213-219.

14 Mocanu V: Prevalence of overweight and obesity in urban elementary school children in northeastern Romania: its relationship with socioeconomic status and associated dietary and lifestyle factors. Biomed Res Int 2013;2013:537451

15 Chirita-Emandi A, Puiu M, Gafencu M, Pienar C: Growth references for school aged children in western Romania. Acta Endocrinologica (Buc) 2012;8:133-152.

16 Chirita-Emandi A, Gafencu M, Pienar C: Impact of increased body mass on growth patterns in school children. Acta Endocrinologica (Buc) 2012;8:551-563.

17 Cinteza E, Balgradean M: Hypertension in Romanian children and adolescents: a cross-sectional survey. Maedica (Buc) 2013;8:5-10.

18 Novac O, Mătăsaru S, Tătaru S, Felea D, Cosmescu A, Stoian M, et al: Clinical and epidemiologic aspects of overweight and nutritional habits of schoolchildren and teenagers (in Romanian). Rev Med Chir Soc Med Nat Iasi 2010;114:721-725.

19 Pelin A-M, Mătăsaru S: Metabolic syndrome in obese children and adolescents (in Romanian). Rev Med Chir Soc Med Nat Iasi 2012;116:957-961.

20 Coman AE, Petrovanu R, Palel G, Petrovanu C, Bogdan A, Codrescu C, et al: Obesity prevalence in Iaşi county (in Romanian). Rev Med Chir Soc Med Nat Iasi 2003;107:113-120.

21 Cattaneo A, Monasta L, Stamatakis E, Lioret S, Castetbon K, Frenken F, et al: Overweight and obesity in infants and pre-school children in the European Union: a review of existing data. Obes Rev 20101;11:389-398.

22 Olaya B, Moneta MV, Pez O, Bitfoi A, Carta MG, Eke C, et al: Country-level and individual correlates of overweight and obesity among primary school children: a cross-sectional study in seven European countries. BMC Public Health 2015;15:475.

23 Nicolescu R: Evaluarea morbidităţii cronice prin dispensarizare în colectivităţile de copii și tineri - raport naţional 2013 - COSI. http://insp.gov.ro/sites/cnepss/wp-content/uploads/2014/12/COSI-2013.pdf (last accessed May 31, 2016).

24 Wijnhoven TM, van Raaij JM, Spinelli A, Starc G, Hassapidou M, Spiroski I, et al: WHO European Childhood Obesity Surveillance Initiative: body mass index and level of overweight among 6-9-year-old children from school year 2007/2008 to school year 2009/2010. BMC Public Health 2014;14-806.

25 Tzioumis E, Adair LS: Childhood dual burden of under- and overnutrition in low- and middle-income countries: a critical review. Food Nutr Bull 2014;35:230-243.

26 Lobstein T, Jackson-Leach R, Moodie ML, Hall KD, Gortmaker SL, Swinburn BA, et al: Child and adolescent obesity: part of a bigger picture. Lancet 2015;385:2510-2520.

27 Connor Gorber S, Tremblay M, Moher D, Gorber B: A comparison of direct vs. self-report measures for assessing height, weight and body mass index: a systematic review. Obes Rev 2007;8:307-326.

28 Wetmore CM, Mokdad AH: In denial: misperceptions of weight change among adults in the United States. Prev Med 2012;55:93-100.

29 de Onis M, Onyango AW, Borghi E, Siyam A, Nishida C, Siekmann J: Development of a WHO growth reference for school-aged children and adolescents. Bull World Health Organ 2007;85:660-667.

30 Cole TJ, Lobstein T: Extended international (IOTF) body mass index cut-offs for thinness, overweight and obesity. Pediatr Obes 2012;7:284-294.

31 National Center for Health Statistics, Centers for Disease Control and Prevention: 2000 CDC growth charts: United States. Hyattsville, MD: National Center for Health Statistics. www.cdc.gov/growthcharts (last accessed May 31, 2016).

32 Human Development Report 2014:Explanatory note on the 2014 Human Development Report composite indices [Internet] 2013 Nov 15;Available from: http://hdr.undp.org/sites/all/themes/hdr_theme/countrynotes/ROU.pdf (last accessed May 31, 2016).

33 Blössner M, Siyam A, Borghi E, Onyango A, de Onis M: WHO AnthroPlus for Personal Computers Manual: Software for Assessing Growth of the World's Children and Adolescents. Geneva, WHO, 2009.

34 BMI Calculator. www.ezbmi.com/bmi-calculator.html (last accessed May 31, 2016).

35 Shields M, Tremblay MS: Canadian childhood obesity estimates based on WHO, IOTF and CDC cut-points. Int J Pediatr Obes 20103;5:265-273.

36 Kêkê LM, Samouda H, Jacobs J, di Pompeo C, Lemdani M, Hubert H, et al: Body mass index and childhood obesity classification systems: a comparison of the French, International Obesity Task Force (IOTF) and World Health Organization (WHO) references. Rev Epidemiol Sante Publique 2015;63:173-182.

37 Brug J, van Stralen MM, te Velde SJ, Chinapaw MJM, De Bourdeaudhuij I, Lien N, et al: Differences in weight status and energy-balance related behaviors among schoolchildren across Europe: the ENERGY-Project. PLoS One 2012;7:34742.

38 Wells JCK: Obesity as malnutrition: the role of capitalism in the obesity global epidemic. Am J Hum Biol 2012; 24:261-276.

39 Hujova Z, Lesniakova M: Anthropometric risk factors of atherosclerosis: differences between urban and rural east-Slovakian children and adolescents. Bratisl Lek Listy 2011;112:491-496.

40 Gurzkowska B, Grajda A, Kułaga Z, Napieralska E, Litwin M: Distribution of body mass index categories among Polish children and adolescents from rural and urban areas. Med Wieku Rozwoj 2011;15:250-257. 
Chirita-Emandi et al.: Overweight and Underweight Prevalence Trends in Children from Romania - Pooled Analysis of Cross-Sectional Studies between 2006 and 2015

41 Farajian P, Risvas G, Karasouli K, Pounis GD, Kastorini CM, Panagiotakos DB, et al: Very high childhood obesity prevalence and low adherence rates to the Mediterranean diet in Greek children: the GRECO study. Atherosclerosis 2011;217:525-530.

42 Johnson JA, Johnson AM: Urban-rural differences in childhood and adolescent obesity in the United States: a systematic review and meta-analysis. Child Obes 2015;11:233-241.

43 Kowal M, Woronkowicz A, Kryst $七$, Sobiecki J, Pilecki MW: Sex differences in prevalence of overweight and obesity, and in extent of overweight index, in children and adolescents (3-18 years) from Kraków, Poland in 1983, 2000 and 2010. Public Health Nutr $2016 ; 19: 1035-1046$.

44 Whitaker RC, Wright JA, Pepe MS, Seidel KD, Dietz WH: Predicting obesity in young adulthood from childhood and parental obesity. N Engl J Med 1997;337:869-873.

45 Addo OY, Miller BS, Lee PA, Hediger ML, Himes JH: Age at hormonal onset of puberty based on luteinizing hormone, inhibin B, and body composition in preadolescent U.S. girls. Pediatr Res 2014;76:564-570.

46 Chirita-Emandi A, Puiu M, Gafencu M, Pienar C: Overweight and obesity in school age children in western Romania. Rev Med Chir Soc Nat Iasi 2013;117:36-45.

47 INSSE - Statistical DB - TEMPO-Online time series. http://statistici.insse.ro/shop/?lang=en (last accessed May $31,2016)$. 